\title{
New Research Directions in the Genus Eulemur: Preface to the Special Issue
}

\author{
Giuseppe Donati $^{1} \cdot$ Steig E. Johnson ${ }^{2}$
}

Published online: 27 February 2016

(C) Springer Science+Business Media New York 2016

\begin{abstract}
Although initially neglected in favor of more charismatic lemurs, the genus Eulemur has been the focus of a growing body of research in Madagascar over the last two decades. These studies have revealed striking variability in the behavioral ecology of this genus. The wide distribution of Eulemur species and the occupancy of essentially all forested habitats in Madagascar have been facilitated by inter- and intrapopulation differences in activity patterns, social organization, body size, and diet (cf. Sato et al., this issue). This adaptability, coupled with the recent evolutionary divergence within the genus, make the Eulemur group an ideal model to study ongoing adaptive radiation.

To bring these new findings together, we organized a symposium at the 25 th Congress of the International Primatological Society in Hanoi in 2014, inviting researchers from Madagascar, Canada, Germany, Italy, Japan, the United Kingdom, and the United States to participate in the first forum dedicated to brown lemurs. This symposium was inspired by Tattersall and Sussman (1998), who first lamented a deficiency of scientific attention to this fascinating group. This lack of interest, driven by the relative inconspicuousness of the brown lemurs, suggested an analogy to the nondescript bird species often dismissed by ornithologists as "little brown jobs" (Tattersall and Sussman 1998). This special issue includes most of the contributions to the Hanoi symposium, with papers exploring links between variation in ecological, behavioral, and anatomical traits within the brown lemur radiation and in comparison with other lemur taxa. We hope that the research presented in this issue will contribute to the continued growth of scientific interest in these "little brown lemurs."
\end{abstract}

Giuseppe Donati

gdonati@brookes.ac.uk

Steig E. Johnson

steig.johnson@ucalgary.ca

1 Department of Social Sciences, Oxford Brookes University, Oxford OX3 0BP, United Kingdom

2 Department of Anthropology and Archaeology, University of Calgary, Calgary, Alberta T2N 1N4, Canada 
In their editorial, Tattersall and Sussman provide a synthesis of the contributions included in this special issue and emphasize the expansion of our knowledge of the genus Eulemur over the last two decades. The unprecedented attention to these taxa results in a wider appreciation of their behavioral and ecological ranges but it also triggers the examination of a variety of more general questions about speciation and adaptation in the evolution of primates and mammals more broadly. We would like to thank all of the authors in this special issue, as well as all the authors who contributed to the symposium and the congress organizers in Hanoi. We also extend our gratitude to Hellen Bersacola, who created the beautiful cover illustration and to Peter Kappeler and Tina Jensen, who provided the photograph of Eulemur rufifrons at Kirindy Forest that inspired the illustration. Finally, our great appreciation goes to Jo Setchell for her tremendous support and guidance from concept to completion of this special issue.

\section{References}

Tattersall, I., \& Sussman, R. (1998). "Little brown lemurs" of northern Madagascar. Folia Primatologica, 69(Suppl. 1), 379-388 